\title{
APLIKASI MONITORING BAGIAN SALES PROMOTION PADA PT. MULTI GARMEN JAYA BERBASIS ANDROID
}

\author{
Ridwan', Toni Arifin ${ }^{2}$ \\ 1 Universitas Adhirajasa Reswara Sanjaya \\ e-mail: ridwan.coustic@gmail.com \\ ${ }^{2}$ Universitas Adhirajasa Reswara Sanjaya \\ e-mail: toni.arifin@ars.ac.id
}

\begin{abstract}
Abstrak
PT. Multi Garmen Jaya merupakan salah satu perusahaan yang bergerak dalam bidang manufaktur garmen. Dalam proses pemasarannya perusahaan ini membuat counter pada salah satu department store yang telah bekerja sama secara retailing. Proses pembuatan laporan penjualan juga pengecekan barang pada setiap counter produk masih bersifat konvensional. Sales akan menghitung hasil penjualan kemudian mengirimkan laporannya melalui pesan whatsapp. Proses tersebut membuat pihak SPV perlu memeriksa serta memberikan himbauan kepada karyawannya untuk segera memberikan laporan pada akhir shift. Pada penelitian ini, penulis melakukan perancangan aplikasi monitoring yang dapat menghitung secara otomatis data yang telah diinputkan, menyimpan histori laporan, dan mengecek ketersediaan barang juga dapat memberikan reminder dan push notification ketika karyawan belum juga mengirimkan laporan pada SPV. Aplikasi ini dirancang dengan menggunakan metode SDLC model waterfall dan firebase sebagai penyimpanan data. Berdasarkan hasil pengujian, aplikasi monitoring karyawan bagian Sales Promotion pada PT. Multi Garmen Jaya berbasis android dapat membantu SPV dalam melakukan monitoring karyawan dan mempermudah Sales Promotion dalam pembuatan laporan penjualan harian juga mengecek ketersediaan barang di counter.
\end{abstract}

Kata Kunci: Android, Monitoring, Sales Promotion, PT. Multi Garmen Jaya

\begin{abstract}
PT. Multi Garmen Jaya is one of the companies engaged in garment manufacturing. In the process of marketing this company makes a counter in one of the department stores that have collaborated in retail. The process of making a sales report also checks the items at each product counter are still conventional. Sales will calculate sales results and then send a report via whatsapp message. The process makes SPV need to check and give an appeal to its employees to immediately provide a report at the end of the shift. In this study, the authors designed a monitoring application that can automatically calculate data entered, store report history, and check item availability and also provide reminders and push notifications when employees have not sent reports to SPV. This application was designed using the SDLC method of the waterfall and firebase models as data storage. Based on the test results, the employee monitoring application of sales promotion section at PT. Multi Garmen Jaya based on Android can help SPV monitor employees and make it easy for Sales Promotions to make daily sales reports and check the availability of goods at the counter.
\end{abstract}

Keywords: Android, Monitoring, Sales Promotion, PT. Multi Garmen Jaya 


\section{Pendahuluan}

Kemajuan ilmu pengetahuan dan teknologi saat ini begitu pesat dan berkembang terhadap kemajuan dalam dunia bisnis. Adanya teknologi membuat sektor perusahaan dapat bekerja secara maksimal. Salah satu manfaat pentingnya yaitu mempermudah proses komunikasi dan monitoring setiap karyawan yang sedang bekerja pada sebuah instansi atau perusahaan (Julaikah, 2016).

PT. Multi Garmen Jaya merupakan salah satu perusahaan yang bergerak dalam bidang manufaktur garmen. Perusahaan ini tidak hanya memproduksi suatu produk pakaian atau jeans, namun sekaligus memasarkannya. Salah satu sistem pemasarannya yaitu dengan cara sistem konsinyasi atau yang lebih dikenal dengan bagi hasil. Sistem konsinyasi ini dilakukan dengan cara counter, fixture, Sales Promotion Girls, dan display (MGJ.com, 2017).

Melalui produknya PT. Multi Garmen Jaya bekerja sama untuk penjualan secara retailing melalui Department Store, salah satunya Yogya Riau Junction. Berdasarkan hasil wawancara dari salah satu karyawan bagian Sales Promotion, tidak tersedianya inventaris seperti komputer dan tab dikarenakan terbatasnya area lokasi counter untuk memajang produk membuat proses pengecekan ketersediaan barang, memberi laporan, menghitung penjualan harian, dan persentase penjualan masih secara konvensional. Data yang telah dihitung kemudian dikirimkan melalui grup aplikasi whatsapp. Proses ini juga membuat pihak SPV harus memeriksa satu persatu karyawan mana yang telah memberikan laporan juga memberi himbauan kepada karyawan yang memang belum untuk segera memberikan laporan di akhir shift toko.

Oleh karena itu, dibutuhkan aplikasi monitoring yang dapat menghitung secara otomatis data yang telah dimasukkan, menyimpan histori laporan dan mengecek ketersediaan barang di database, juga memberikan reminder dan push notification ketika karyawan belum juga mengirimkan laporan pada SPV.

Beberapa penelitian sebelumnya mengenai aplikasi monitoring sales partner pada PT. Coca Cola Amatil Indonesia Banjarbaru(Putra \& Soegiarto, 2016). Kemudian penelitian lainnya, sistem monitoring barang cetak berbasis web
(Nawawi et al., 2019). Serta, rancang bangun aplikasi informasi perkuliahan berbasis android (Salamah et al., 2019).

Berdasarkan pemaparan sebelumnya, maka penulis bermaksud membuat aplikasi monitoring karyawan bagian Sales Promotion pada PT. Multi Garmen Jaya berbasis android. Tujuannya untuk memudahkan para pegawai dalam mengecek ketersediaan barang dan melakukan perhitungan laporan harian yang masih bersifat konvensional secara cepat dan tepat waktu, juga membantu pihak SPV untuk melakukan monitoring karyawannya dalam hal menerima laporan harian dan memberikan informasi mengenai perubahan target yang akan dicapai melalui smartphone pribadi. Aplikasi ini berjalan pada platform android agar pengguna dapat melakukan laporan dan memberikan informasi dimana saja baik itu untuk SPV ataupun Sales Promotion.

\section{Metode Penelitian}

\subsection{Teknik Pengumpulan Data}

Pengumpulan data menjadikannya sebagai informasi yang akan digunakan untuk mengetahui permasalahan yang terjadi. Adapun teknik pengumpulan data yang digunakan dalam penelitian ini, yaitu:

\section{Wawancara}

Wawancara ditujukan kepada salah satu karyawan PT. Multi Garmen Jaya bagian Sales Promotion yang ditempatkan pada counter produk cabang Yogya Riau Junction

\section{Studi Pustaka}

Pengumpulan data dilakukan dengan cara mempelajari literature atau sumber yang berkaitan dengan masalah yang diteliti. Data yang berupa informasi tersebut diperoleh dari jurnal atau tulisan pada situs internet yang berkaitan dengan sistem informasi mengenai metode pemrograman mobile dan informasi yang mendukung pada pembuatan aplikasi ini.

\subsection{Metode Pengembangan Sistem}

Metode yang digunakan dalam penelitian ini adalah model waterfall. Model Waterfall merupakan suatu proses pengembangan program komputer yang di mana proses pengerjaannya terus mengalir secara berurutan dari atas ke bawah (Zaenul et al., 2017). Secara garis besar metode ini 
mempunyai langkah-langkah mulai dari tahap Requirement Analyst, Design, Implementation, Verification, dan Maintenance (Sofyan et al., 2019).

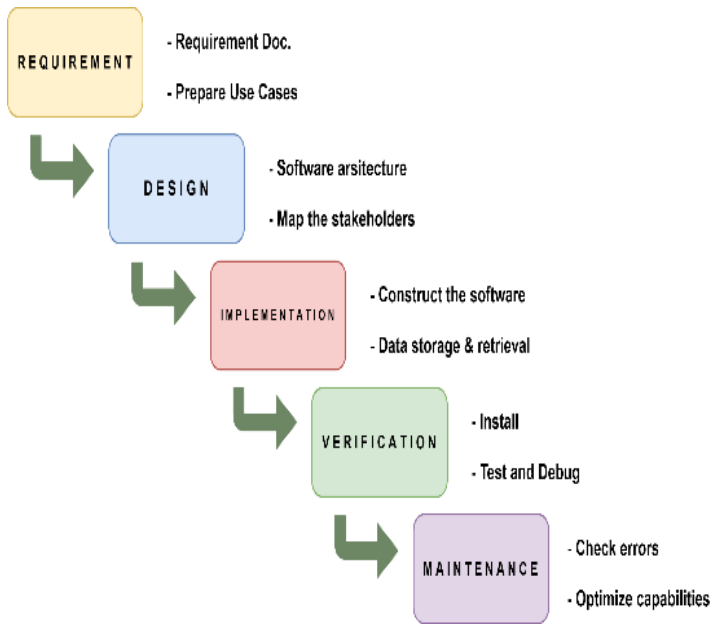

Gambar 1. SDLC Waterfall

Sumber : (Rahim, 2018)

\subsection{Desain}

Tahapan selanjutnya dalam model waterfall adalah desain yang merupakan bagian dalam proses menerjemahkan seluruh kebutuhan perangkat lunak yang telah di analisa pada sebuah perancangan perangkat lunak yang dapat diperkirakan sebelum melakukan proses coding atau implementasi program.

\subsubsection{Database}

Perancangan basis data merupakan proses yang digunakan dalam menentukan isi dan pengaturan data yang dibutuhkan untuk mendukung berbagai rancangan sistem atau aplikasi. Perancangan basis data yang digunakan dalam penelitian ini adalah menggunakan Firebase. Menurut Syukri \& Setiawan dalam Suparman \& Arifin (2017) firebase adalah layanan DbaaS (Database as a Service) dengan konsep real time. Firebase merupakan penyedia layanan cloud dengan backend sebagai service.

\section{Hasil dan Pembahasan \\ 3.1. Perancangan Sistem}

Perancangan sistem pada penelitian kali ini akan menghasilkan beberapa fitur pada masing-masing user. Pemodelan dan perancangan sistem digambarkan dengan menggunakan UML (Unifield Modeling Language). Menurut Rosa dan Shalahuddin dalam jurnal E. W. Fridayanthie \& Mahdiati
(2016) UML (Unified Modeling Language) adalah salah satu standar bahasa yang banyak digunakan di dunia industri untuk medefinisikan requirement, membuat analisis dan desain, serta menggambarkan arstitektur dalam pemograman berorientasi objek.

Tahap-tahap pemodelan yang digunakan dalam penelitian ini yaitu Use Case Diagram, Activity Diagram, Sequence Diagram, dan Class Diagram.

\section{Use Case Diagram}

Use case diagram merupakan diagram yang digunakan untuk mengetahui fungsi apa saja yang terdapat dalam sebuah sistem juga untuk mempresentasikan sebuah interaksi antara aktor dengan sistem.

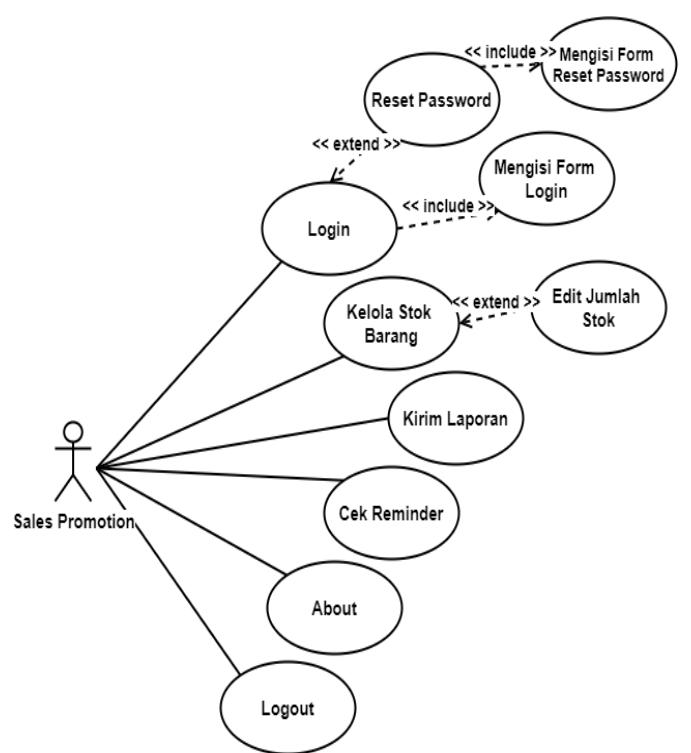

Gambar 2. Use Case Diagram Sales Promotion

Dari gambar 2 dapat dilihat pada aplikasi ini terdiri dari 1 aktor dan 10 Use Case. 


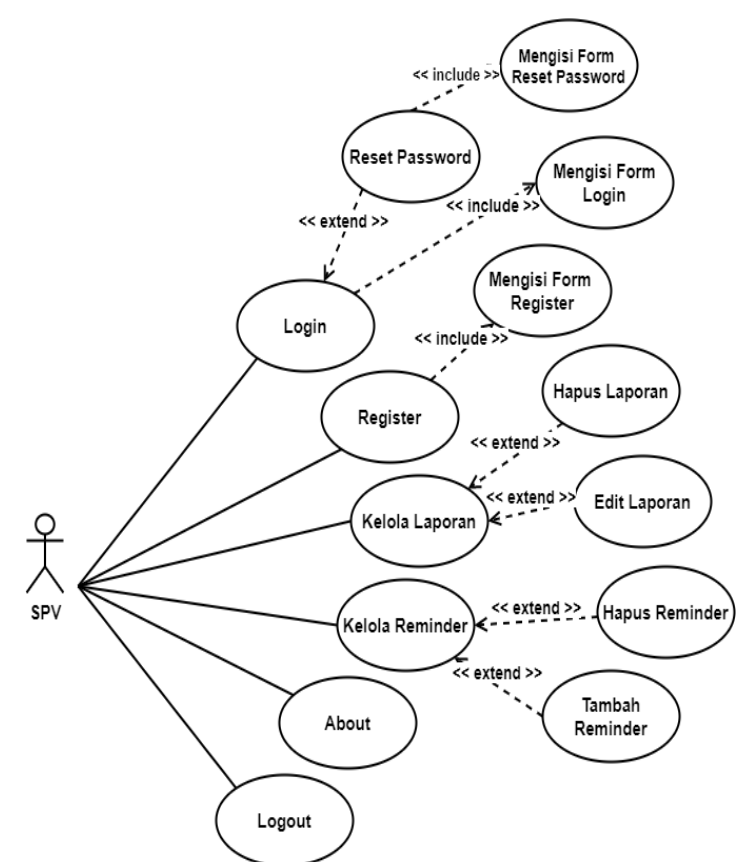

Gambar 3. Use Case Diagram SPV

Dari gambar 3 dapat dilihat pada aplikasi ini terdiri dari 1 aktor dan 14 Use Case

\section{Class Diagram}

Diagram struktur statis yang menggambarkan struktur aplikasi yang akan dibangun berisi nama kelas sistem, method atau operasi, atribut, juga hubungan antar kelas dapat digambarkan menggunakan class diagram pada Gambar 4.

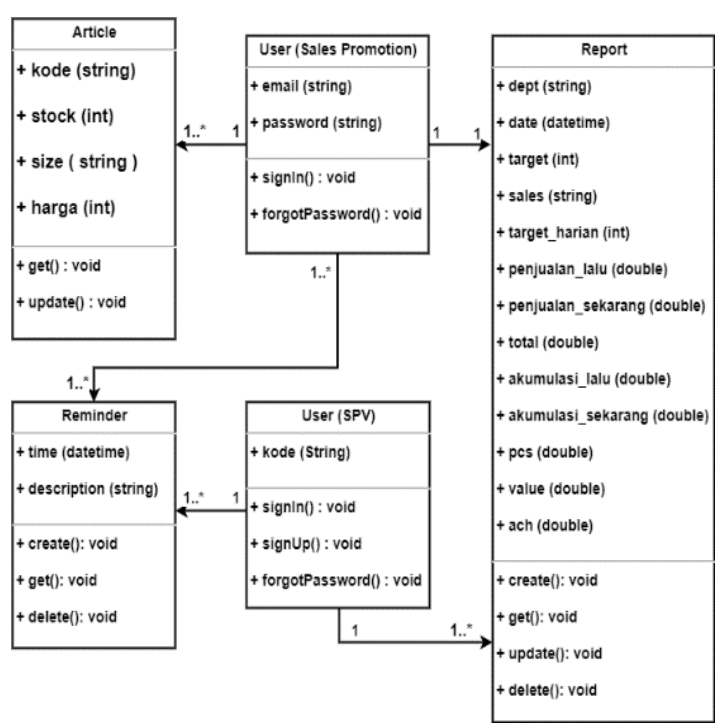

Gambar 4. Class Diagram Aplikasi

\subsection{Implementasi}

Implementasi merupakan tahap penciptaan aplikasi yang dibuat berdasarkan hasil dari analisis serta didesain secara terinci pada tahap sebelumnya. Berikut merupakan beberapa tampilan implementasi antarmuka pada aplikasi monitoring karyawan bagian Sales Promotion pada PT. Multi Garmen Jaya berbasis android.

\section{Tampilan Aplikasi Utama}

Aplikasi Rekapp ini memiliki dua user dalam satu aplikasi, dimana ketika login dengan e-mail yang telah terdaftar akan otomatis masuk sesuai dengan posisi/jabatan user.

Tampilan Utama dari Aplikasi Rekapp sebagai berikut :

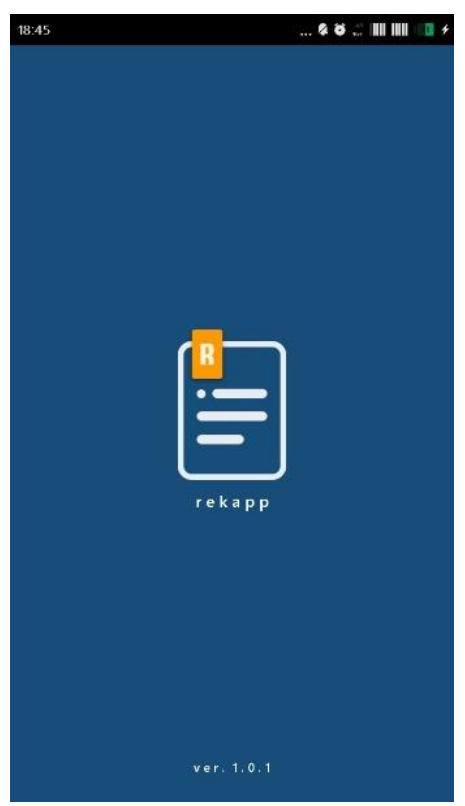

Gambar 5. Tampilan Splash Screen 


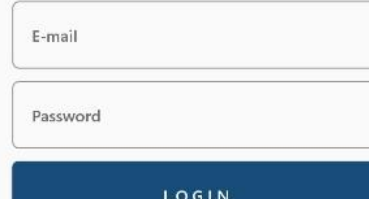

LOGIN

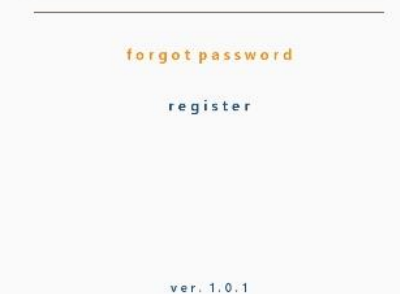

Gambar 6. Tampilan Login

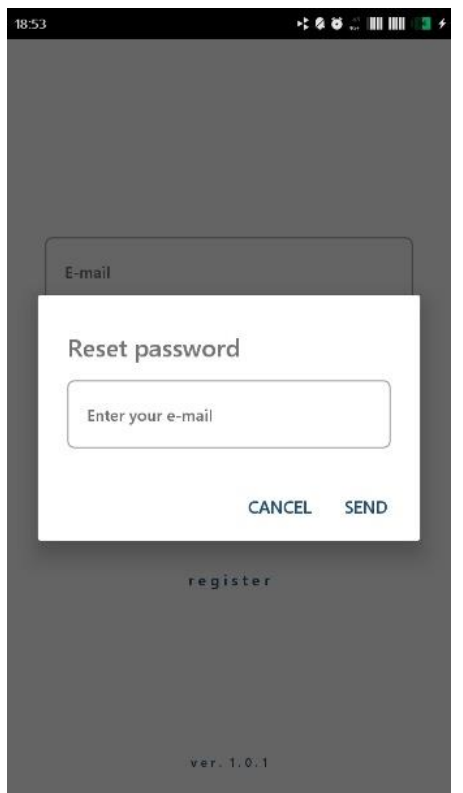

Gambar 7. Tampilan Reset Password

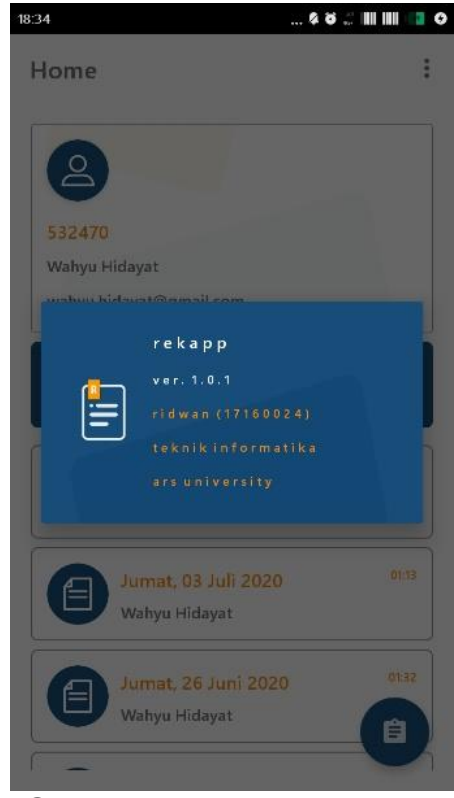

Gambar 8. Tampilan About

\section{Tampilan Aplikasi Sales Promotion}

Pada saat user memasukkan email, maka sistem secara otomatis akan mendeteksi posisi/jabatan dari user tersebut. Jika user sebagai Sales Promotion maka akan menampilkan halaman sebagai berikut :

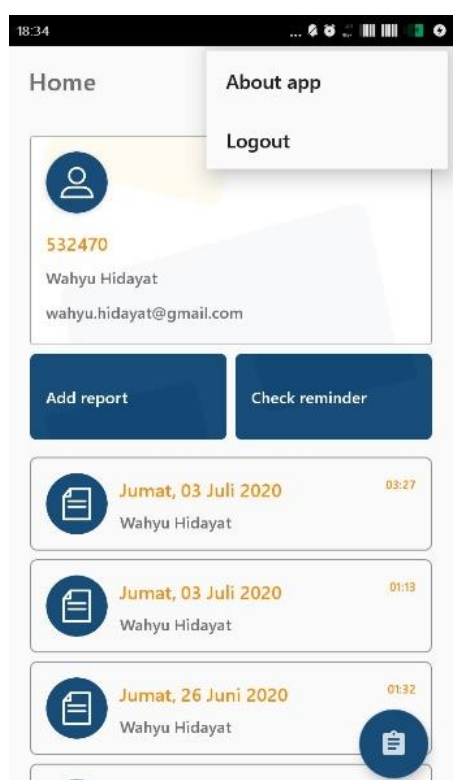

Gambar 9. Tampilan Menu Utama Sales Promotion 


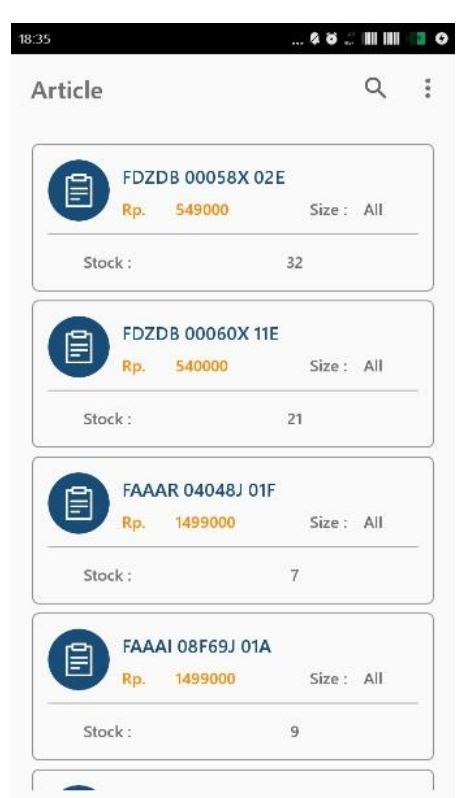

Gambar 10. Tampilan Article Product

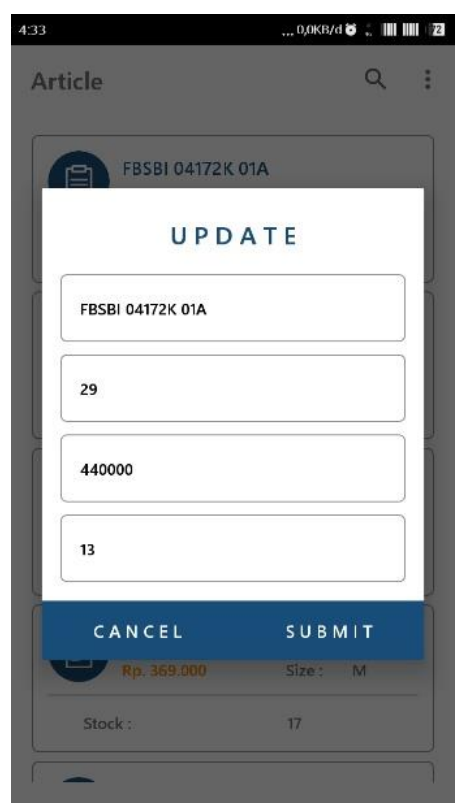

Gambar 11. Tampilan Ubah Produk

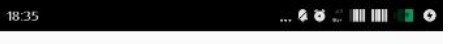

Check Reminder

Jumat, 26 Juni 2020

Perubahan jadwal untuk seluruh pega...

Gambar 12. Tampilan Cek Reminder

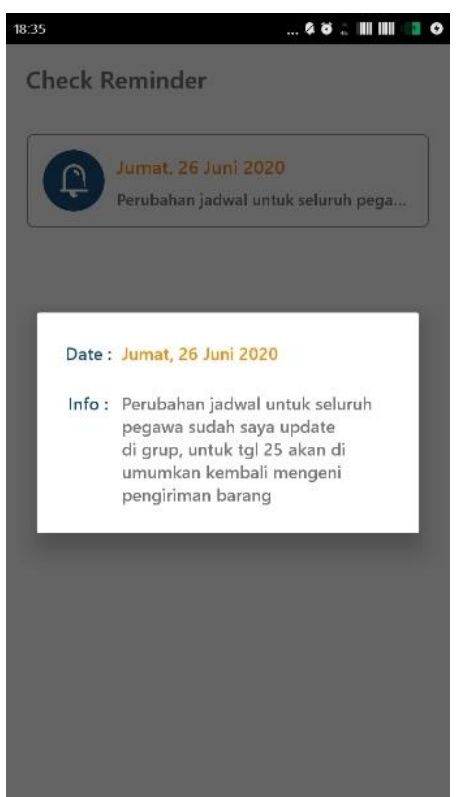

Gambar 13. Tampilan Detail Reminder 


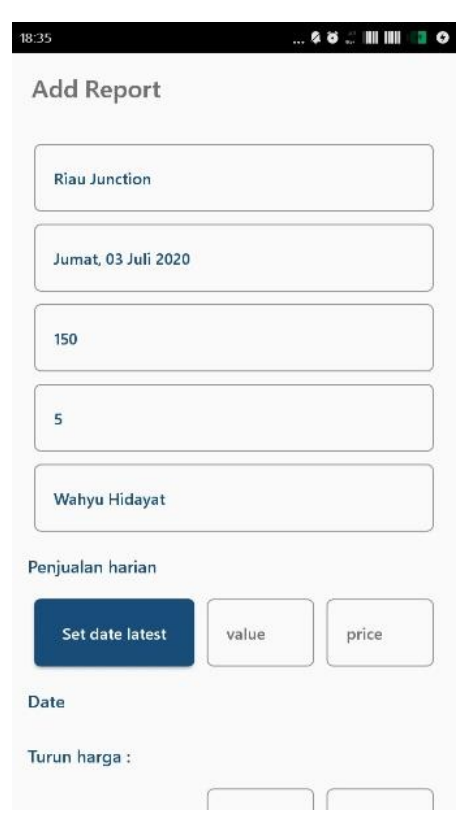

Gambar 14. Tampilan Tambah Laporan

\section{Tampilan Aplikasi SPV}

Pada saat user memasukkan $e$ mail, maka sistem secara otomatis akan mendeteksi posisi/jabatan dari user tersebut. Jika user sebagai Sales Promotion maka akan menampilkan halaman sebagai berikut :

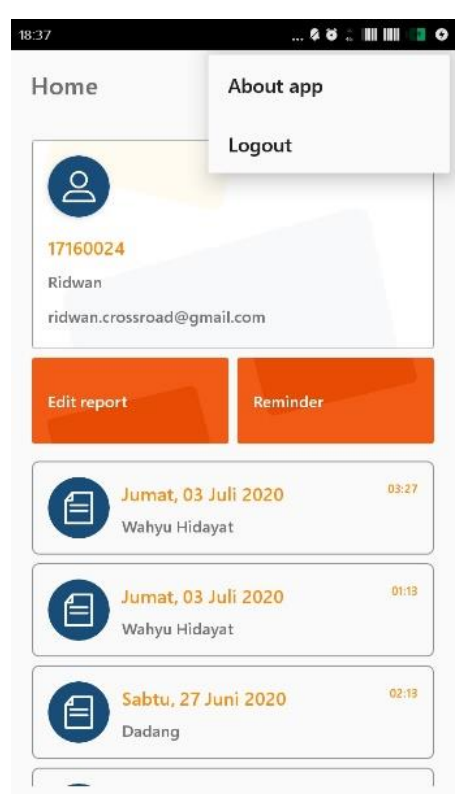

Gambar 15. Tampilan Menu Utama SPV

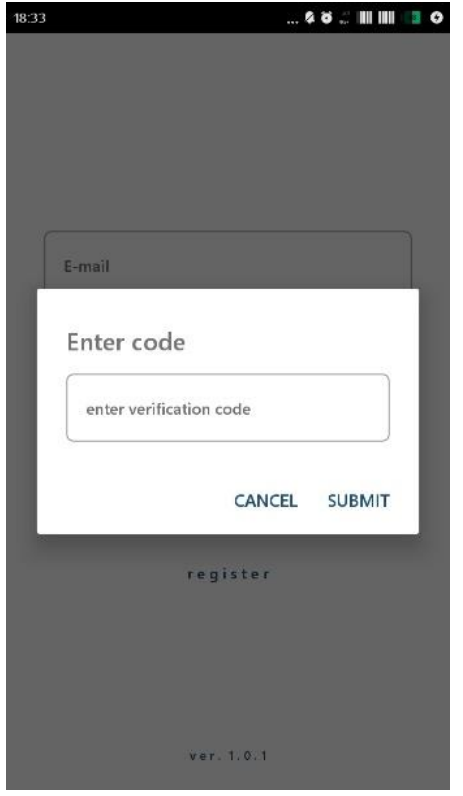

Gambar 16. Tampilan Verifikasi Kode

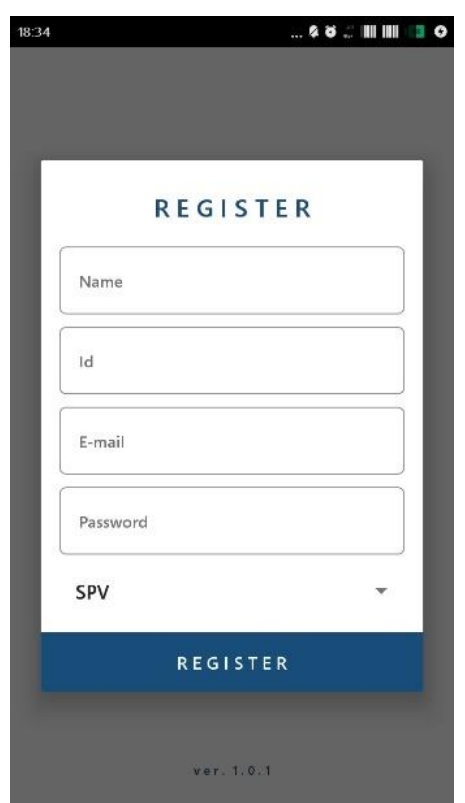

Gambar 17. Tampilan Register 


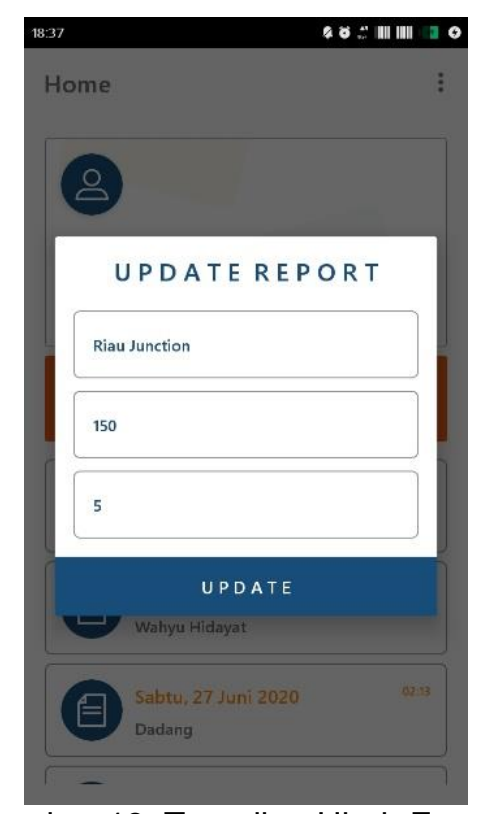

Gambar 18. Tampilan Ubah Format Laporan

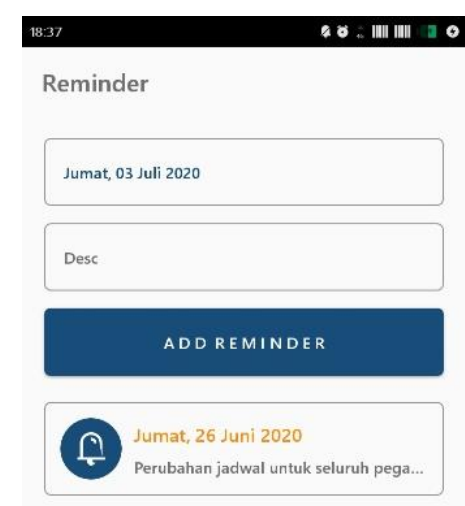

Gambar 19. Tampilan Tambah Reminder

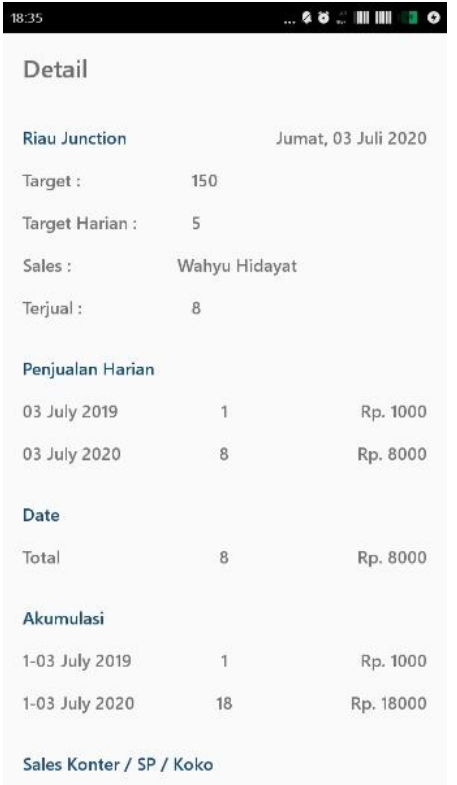

Gambar 20. Tampilan Detail Laporan

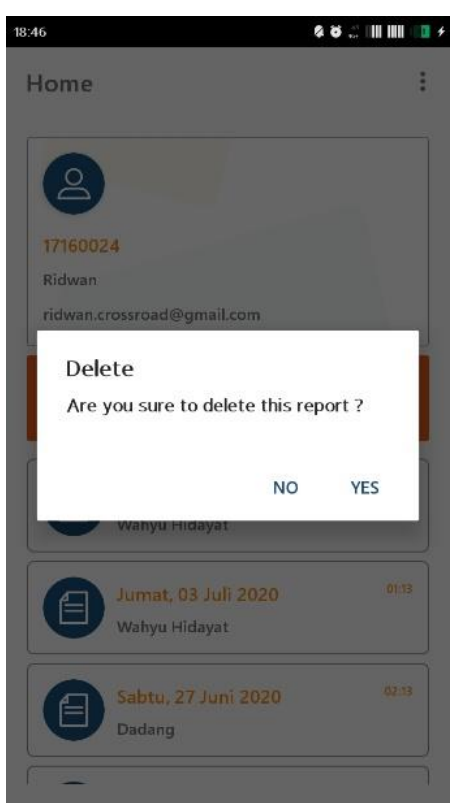

Gambar 21. Tampilan Hapus Laporan 


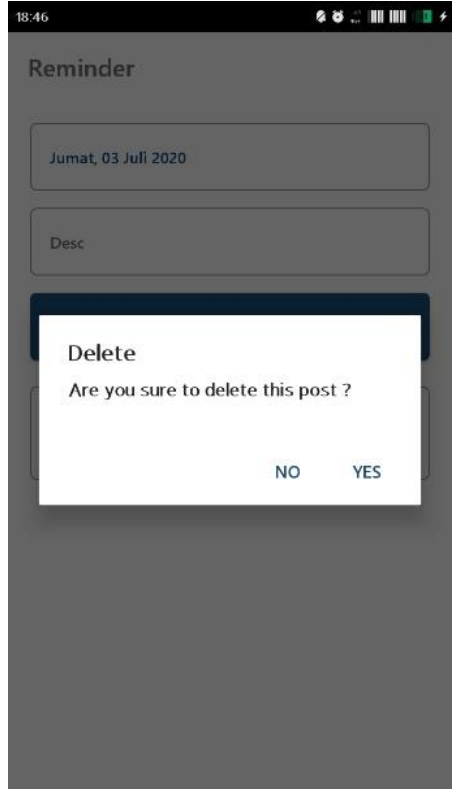

Gambar 22. Tampilan Hapus Reminder

\subsection{Hasil Pengujian}

Hasil pengujian menggunakan metode black-box testing pada aplikasi ini sebagai berikut:

Pengujian Aplikasi yang dijalankan dengan user sebagai Sales Promotion menghasilkan tujuh Modul Pengujian diantaranya :
a. Login Sales
b. Lihat Article
c. Ubah Article
d. Cek Reminder
e. Kirim Lopran
f. Terima Notifikasi
g. Reset Kata Sandi

Hasil pengujian modul diatas dapat disimpulkan mendapatkan hasil valid atau sesuai dengan result expectation dari user sebagai Sales Promotion.

Pengujian Aplikasi yang dijalankan dengan user sebagai SPV menghasilkan enam Modul Pengujian diantaranya :
a. Login SPV
b. Register
c. Tambah Reminder
d. Ubah Format Laporan
e. Reset Kata Sandi
f. Kode Verifikasi

Hasil pengujian modul diatas dapat disimpulkan mendapatkan hasil valid atau sesuai dengan result expectation dari user sebagai SPV.

\section{Kesimpulan}

Berdasarkan hasil pembahasan dan pengujian yang telah dilakukan, maka penulis dapat menarik beberapa kesimpulan sebagai berikut:

1. Aplikasi dapat membantu pihak SPV dalam melakukan monitoring karyawan dengan memberikan reminder yang berupa push notifikasi secara otomatis ketika karyawan belum memberikan laporan penjualan harian.

2. Aplikasi ini dapat memudahkan Sales Promotion dalam mengecek ketersediaan barang yang dijual di counter juga mengefisienkan waktu ketika melakukan laporan penjualan harian karena aplikasi telah disisipkan perhitungan berdasarkan data yang telah diinputkan.

Saran yang mungkin bermanfaat bagi para pengembang berikutnya agar aplikasi yang telah dibangun menjadi lebih baik antara lain, aplikasi dapat dikembangkan menjadi aplikasi hybrid yang dapat berfungsi pada platform IOS dan Android, menambah fitur penjadwalan dan perhitungan bonus karyawan, dan menambahkan fitur scan article pada menu article agar lebih memudahkan pengguna Sales Promotion dalam melakukan perubahan data article product.

\section{Referensi}

Fridayanthie, E. W., \& Mahdiati, T. (2016). $\begin{array}{llr}\text { RANCANG } & \text { BANGUN SISTEM } \\ \text { INFORMASI } & \text { PERMINTAAN ATK }\end{array}$ BERBASIS INTRANET (STUDI KASUS: KEJAKSAAN NEGERI RANGKASBITUNG). JURNAL KHATULISTIWA INFORMATIKA, 3(1), 56.

https://doi.org/https://doi.org/10.3929/ ethz-b-00023866

Julaikah, E. (2016). Manfaat Teknologi Informasi di Bidang Bisnis. https://www.kompasiana.com/emijulai $\mathrm{kah} / 57492108337 \mathrm{~b} 61 \mathrm{ad0f7fa86a/man}$ faat-teknologi-informasi-di-bidangbisnis 
MGJ.com. (2017). PT. Multi Garmen Jaya. https://multigarmenjaya.com/

Nawawi, I., Abdilah, A., \& Nurajijah, N. (2019). Inti Nusa Mandiri Sistem Monitoring Barang Cetak Berbasis Web. Inti Nusa Mandiri, 14(1), 77-84.

Putra, M., \& Soegiarto. (2016). Aplikasi Monitoring Sales Partner Pada PT . Coca Cola Amatil Indonesia Banjarbaru. PROGRESIF, 12(2), 1495-1503.

Rahim, A. (2018). Perancangan Aplikasi EInformation Dan Jadwal Perkuliahan Berbasis Mobile Android. Jurnal Processor, 12(1), 1000-1010. http://ejournal.stikom-

db.ac.id/index.php/processor/article/vi ew/374

Salamah, I., Lindawati, L., \& Handayani, H. F. (2019). Rancang Bangun Aplikasi Informasi Perkuliahan Berbasis Android. Jurasik (Jurnal Riset Sistem Informasi Dan Teknik Informatika), 4(1), https://doi.org/10.30645/jurasik.v4i1.1 11

Sofyan, A. P., Arifin, T., \& Fauzi, A. (2019). APLIKASI PEMESANAN MAKANAN MINUMAN BERBASIS ANDROID PADA RUMAH MAKAN SUSHI ZEN RAMEN.

Suparman, J., \& Arifin, T. (2017). RANCANG BANGUN APLIKASI SISTEM INFORMASI AKADEMIK DAN NON AKADEMIK SEKOLAH BERBASIS ANDROID MENGGUNAKAN FIREBASE. 1-10. http://digilib.ars.ac.id/index.php?p=sho $\mathrm{w}$ _detail\&id $=5248 \&$ keywords $=$

Zaenul, A., Maxsi, A., \& Yosep, H. (2017). Sistem Informasi Monitoring Chart Penjualan Berbasis Web Pada Fatcow Steak House Bandung. 2(September). 